\title{
Comparison of adsorption affinity of polyacrylic acid for surfaces of mixed silica-alumina
}

\author{
Małgorzata Wiśniewska • Teresa Urban • \\ Elżbieta Grządka • Vladimir I. Zarko • \\ Vladimir M. Gun'ko
}

Received: 11 September 2013 /Revised: 18 October 2013 / Accepted: 22 October 2013 /Published online: 23 November 2013

(C) The Author(s) 2013. This article is published with open access at Springerlink.com

\begin{abstract}
The influence of solution $\mathrm{pH}$ (in the range 3-9) on the adsorption of polyacrylic acid (PAA) on the mixed silicaalumina surface (SA-3: $\mathrm{SiO}_{2} 97 \%-\mathrm{Al}_{2} \mathrm{O}_{3} 3 \%$ and SA-96: $\mathrm{SiO}_{2} 4 \%-\mathrm{Al}_{2} \mathrm{O}_{3} 96 \%$ ) was investigated. The following methods were applied in experiments: spectrophotometry, viscosimetry, potentiometric titration, and microelectrophoresis, which enable determination of adsorbed amount of the polymer, thickness of its adsorption layers, surface charge density, and zeta potential of solid particles in the presence and absence of PAA, respectively. The obtained results indicate that rise of solution $\mathrm{pH}$ causes the decrease of PAA adsorption and the increase of its adsorption layer thickness on surfaces of both solids. Moreover, significantly higher adsorption of polyacrylic acid was obtained on the SA-96 surface. This is a result of more favorable electrostatic interactions occurring between the adsorbing polymer chains and the SA-96 surface and formation of a greater number of adsorbate-adsorbent connections through hydrogen bridges.
\end{abstract}

Keywords Polyacrylic acid · Mixed silica-alumina $\cdot$ Polymer conformation $\cdot$ Adsorption $\cdot$ Zeta potential

\section{Introduction}

The adsorption process of various substances (low molecular and macromolecular) [1-4] is very important for many

\author{
M. Wiśniewska $(\triangle) \cdot$ T. Urban • E. Grządka \\ Department of Radiochemistry and Colloid Chemistry, Faculty of \\ Chemistry, Maria Curie Sklodowska University, Maria Curie \\ Sklodowska Sq. 3, 20-031 Lublin, Poland \\ e-mail: wisniewska@hektor.umcs.lublin.pl
}

V. I. Zarko $\cdot$ V. M. Gun'ko

National Academy of Sciences of Ukraine, Institute of Surface

Chemistry, 17 General Naumov Street, 03164 Kiev, Ukraine practical applications. The polymeric compounds turned out to be very effective in the role of substances used to control colloidal systems stability. The specific conformation of macromolecular chains adsorbed on the surface of colloidal particle is essential for stabilization or destabilization of such systems [5-8]. The research concerning the adsorption of polymeric substances at the solid-liquid interface is very crucial due to wide usage of such systems in many fields of human activity. The most important of them are production of cosmetics, pharmaceuticals, paint, paper, food processing, drinking water purification, wastewater treatment, flotation, mineral processing, agriculture (reduction of cultivated soil erosion), and oil recovery [9-16].

Such huge demand for efficient stabilizers and flocculants of industrial colloidal suspensions makes that basic studies of the adsorption mechanism of polymers on the solid surface, which directly affects the stability of suspension in the presence of macromolecular compound, is very important.

In order to determine the mechanism of the processes taking place during the contact of the polymer solution with a solid surface, there must be taken into account the kind and structure of the macromolecular compound, the surface properties of metal oxide, as well as the type of interactions taking place between them. The precise characteristics of the conformation of adsorbed macromolecules and the impact of various factors on final conformation of adsorbed macromolecules can provide information on the structure of the polymer adsorption layer. This can be done based on the experimentally determined parameters, of which the most important are the amount of adsorbed polymer, its adsorption layer thickness, surface charge, and zeta potential of solid particles in the presence of polymer. The specific placement of the adsorbed polymer chains on the solid surface depends, among others, on the molecular weight of the polymer, its kind (anionic, cationic, and nonionic), concentration, and type of surface groups of the metal oxide, solution $\mathrm{pH}$, and temperature. 
Thus, the aim of this work is to determine the adsorption mechanism of anionic polyacrylic acid (PAA) on the mixed silica-alumina surface. As mentioned above, the conformation of the adsorbed polymer chain (especially ionic) depends on many factors; the influence of three of them (solution $\mathrm{pH}$, polymer molecular weight, and metal oxide type) was investigated. Two mixed oxides, differing in chemical composition, were applied in the experiments: $\mathrm{SA}-3: \mathrm{SiO}_{2} 97 \%-\mathrm{Al}_{2} \mathrm{O}_{3} 3 \%$ and SA-96: $\mathrm{SiO}_{2} 4 \%-\mathrm{Al}_{2} \mathrm{O}_{3} 96 \%$. Such small addition of another oxide (of a few percent) to the basic oxide leads to some modification of the solid surface properties, which affects the changes in concentration of surface active groups and the values of the adsorbent $\mathrm{pH}_{\mathrm{pzc}}$ (point of zero charge) and $\mathrm{pH}_{\text {iep }}$ (isoelectric point).

Mixed oxides are widely used as components of ceramics, as catalysts for organic synthesis, adsorbents for various gasses, and toxic ions [17-20].

The performed studies are of fundamental research character; however, the obtained results have important practical aspect. Determination of the stability mechanism of a solidpolymer solution system must be preceded by measurements that lead to characterize the conformation of the polymer chains adsorbed on the adsorbent surface. For this reason, the presented studies very well fit in this scientific trend. Our previous research indicated that the polyacrylic acid presence in the systems containing both mixed oxides (SA-3 and SA-96) has pronounced impact on suspension stability (both stabilizing and destabilizing, depending on solution $\mathrm{pH}$ and polymer molecular weight) $[21,22]$.

\section{Experimental}

The samples of mixed silica-alumina were used in the study (pilot plant in the Chuiko Institute of Surface Chemistry, Kalush, Ukraine). Applied oxides were prepared using chemical vapor deposition method [23]. The physicochemical characteristics of these adsorbents and their symbols are placed in Table 1. The BET surface area and the mean pore diameter were determined by the low-temperature nitrogen adsorptiondesorption isotherm method (Micrometritics ASAP 2405 analyzer). The mean grain sizes of applied solids were obtained using photon correlation spectroscopy (Zetasizer 3000, Malvern Instruments).

Polyacrylic acid (Fluka) with the weight average molecular weights $2,000,100,000$, and 240,000 was used in the experiments. The functional groups of PAA chains are carboxyl $(-\mathrm{COOH})$ ones. As a result of the $\mathrm{pH}$ increase, the dissociation of functional groups occurs. The pKa of the PAA is 4.5 [24], which means that at $\mathrm{pH}$ below 4.5 functional groups in the polymer chains are predominantly undissociated (at $\mathrm{pH} 3$, the degree of these groups dissociation $(\alpha)$ is equal to 0.03 ). At $\mathrm{pH} 4.5$, the number of $-\mathrm{COOH}$ groups is the same as $-\mathrm{COO}^{-}$ ones $(\alpha=0.5)$. As the $\mathrm{pH}$ rises above $4.5^{\circ}$ of polyelectrolyte dissociation increases rapidly; at $\mathrm{pH} 6$, it is equal to 0.97 and at pH 9 reaches a value close to 1 [25].

All measurements were carried out in the presence of $\mathrm{NaCl}$ solution $\left(1 \cdot 10^{-2} \mathrm{~mol} \mathrm{dm}^{3}\right)$ which was used as the supporting electrolyte. Adsorption, viscosity, and electrokinetic experiments were performed at the solution $\mathrm{pH} 3,6$, and 9 at $25^{\circ} \mathrm{C}$. The appropriate $\mathrm{pH}$ values of the investigated systems were adjusted using a pH meter PHM 240 (Radiometer) with the accuracy \pm 0.1 .

The adsorbed amounts of the polymer were determined by the static method using the following polymer concentrations: $10,20,30,50,70,100$, and $200 \mathrm{ppm}$. Before the solid addition, the appropriate solution $\mathrm{pH}(3,6$, or 9$)$ was adjusted with $\mathrm{HCl}$ and $\mathrm{NaOH}$ solutions in each sample (with a volume of $10 \mathrm{~cm}^{3}$ ). Then, $0.04 \mathrm{~g}$ of SA-3 (or $0.015 \mathrm{~g}$ of SA-96) was added to each polymer solution, and suspension $\mathrm{pH}$ was checked and adjusted. The prepared suspensions were shaken for about $24 \mathrm{~h}$ in water bath (OLS 200, Grant Inst.), and then the solution $\mathrm{pH}$ was checked again. Afterwards, the solid was centrifuged and $5 \mathrm{~cm}^{3}$ of clear solution were taken for further analysis. The polymer concentration in each sample was determined using hyamine [26] The turbidity of solutions after the hyamine addition was measured after $15 \mathrm{~min}$ at a wavelength $\lambda=500 \mathrm{~nm}$ with a UV/VIS spectrophotometer (Carry 100 Bio, Varian). The amount of adsorbed polymer was determined from the difference in the polymer concentration in the solution before and after the adsorption process using the previously prepared calibration curve (dependency of absorbance of polymer solution versus its concentration).

The thickness of the polymer adsorption layers $(\delta)$ was determined from the viscosity measurements [27] using a
Table 1 Physicochemical characteristic of adsorbents

\begin{tabular}{lllll}
\hline Symbol & Chemical composition & $\begin{array}{l}\text { BET specific } \\
\text { surface area }\left[\mathrm{m}^{2} / \mathrm{g}\right]\end{array}$ & $\begin{array}{l}\text { Mean pore } \\
\text { diameter }[\mathrm{nm}]\end{array}$ & $\begin{array}{l}\text { Mean grain } \\
\text { size }[\mathrm{nm}]\end{array}$ \\
\hline SA-3 & $\mathrm{SiO}_{2}(97 \%) \mathrm{Al}_{2} \mathrm{O}_{3}(3 \%)$ & 302 & 7.7 & 258 \\
SA-96 & $\mathrm{SiO}_{2}(4 \%) \mathrm{Al}_{2} \mathrm{O}_{3}(96 \%)$ & 75 & 7.4 & 176 \\
\hline
\end{tabular}


CVO 50 rheometer (Bohlin Instruments). For this purpose, the following dependencies were used:

$\delta=r\left[\left(\frac{\phi_{p}}{\phi_{0}}\right)^{1 / 3}-1\right]$

Where $r$ is the radius of the solid particle, $\phi_{0}$ is the volume fraction of the solid without polymer, and $\phi_{p}$ is the volume fraction of the solid with polymer.

$\frac{\eta}{\eta_{0}}=1+k \phi_{0}$

Where $\eta$ is the viscosity of the suspension, $\eta_{0}$ is the viscosity of the liquid phase, and $k$ is the Einstein coefficient.

The values of $\phi_{p}$ were obtained from a calibration curve. For this purpose, a few suspensions of mixed oxide corresponded to various volume fractions $\left(\phi_{0}\right)$ of the solid were prepared in the following way: $0.5,1,1.5,2$, and $2.5 \mathrm{~g}$ of the solid were added to $40 \mathrm{ml}$ of $\mathrm{NaCl}$ solutions. Then, these suspensions were shaken for $24 \mathrm{~h}$ in water bath OLS 200 (Grant). After this time, their viscosities $(\eta)$ and viscosities of clear $\mathrm{NaCl}$ solution $\left(\eta_{0}\right)$ were measured. As a result, the $\eta / \eta_{0}=\mathrm{f}\left(\phi_{0}\right)$ dependence was obtained (straight line). An example of calibration curve obtained for SA-3 system is presented in Fig. 1.

The viscosity measurements in the presence of PAA were made with the volume fraction $\left(\phi_{0}\right)$ of SA-3 equal to 1.25 . $10^{-4}$ and SA-96 $1.89 \cdot 10^{-3}$. The value of volume fraction $\left(\phi_{\mathrm{p}}\right)$ corresponding with $\left(\eta / \eta_{0}\right)_{\mathrm{p}}$ ratio in the presence of polymer was read out from the calibration curve. The polymer adsorption causes the increase of volume fraction of dispersed solid. Knowing the radius of the solid particle, the thickness of the adsorbed polymer layer can be calculated using Eq. [1].

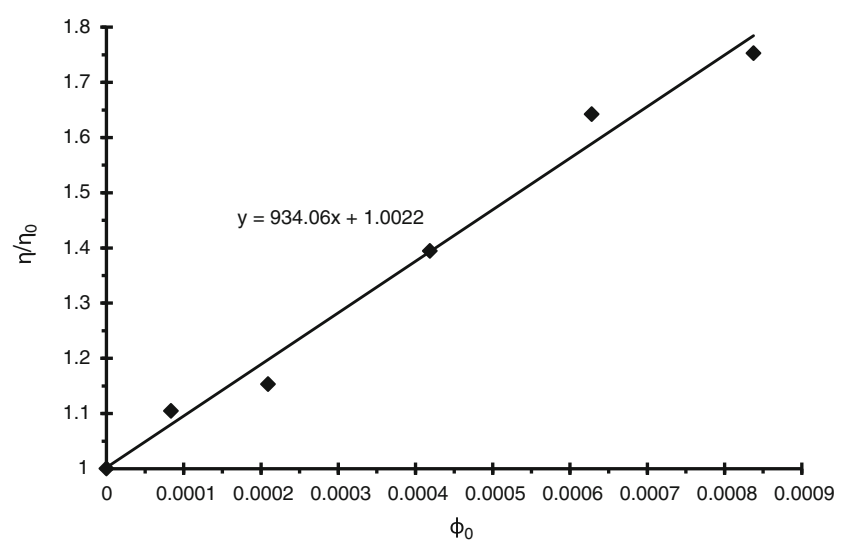

Fig. 1 Dependence of SA-3 suspension relative viscosity $\left(\eta / \eta_{0}\right)$ versus solid volume fraction $\left(\varphi_{0}\right)$
The potentiometric titration method was used to determine the surface charge density of the mixed oxide in the absence and presence of PAA. This method is based on the comparison of titration curve of electrolyte with the titration curve of suspension (containing adsorbent) having the same ionic strength (supporting electrolyte concentration). Such comparison of both titration curves allows determination of the $\mathrm{pH}_{\mathrm{pzc}}$ (point of zero charge, pzc); it is located at the intersection of these two curves. The surface charge density $\left(\sigma_{0}\right)$ is determined from the difference in the volume of base $(\Delta \mathrm{V})$ which must be added to bring the $\mathrm{pH}$ of suspension and electrolyte to the specified value:

$\sigma_{0}=\frac{\Delta V c_{b} F}{m S}$

Where $c_{b}$ is the base concentration, $F$ is the Faraday constant, $m$ is the solid mass in the suspension, $S$ is the specific surface area of the solid.

The experimental setup for these measurements included: Teflon vessel, automatic burette Dosimat 665 (Methrom), thermostat RE204 (Lauda), pH meter 71 pH meter (Beckman), and computer. Special computer program Titr v3 (author: W. Janusz) collected data and performed surface charge density calculations. SA-3 $0.2 \mathrm{~g}$ (or $0.3 \mathrm{~g}$ of SA-96) was added into the thermostated vessel to $50 \mathrm{~cm}^{3}$ of supporting electrolyte solution or polymer solution $\left(\mathrm{C}_{\mathrm{PAA}}=\right.$ $100 \mathrm{ppm}$ ) in the supporting electrolyte. The suspensions prepared in such a way were titrated with the $\mathrm{NaOH}$ solution $\left(1 \cdot 10^{-1} \mathrm{~mol} / \mathrm{dm}^{3}\right)$ in the $\mathrm{pH}$ range $3-10$.

The zeta potentials of mixed oxide particles in the presence and absence of PAA were measured with the Zetasizer 3000 laser zetameter (Malvern Instruments). For that purpose, the suspensions containing $0.04 \mathrm{~g}$ of SA-3 (or $0.01 \mathrm{~g}$ of SA-96) in $500 \mathrm{~cm}^{3}$ of the supporting electrolyte or polymer solution $\left(\mathrm{C}_{\mathrm{PAA}}=0.1 \mathrm{ppm}\right)$ were prepared. This suspension was ultrasonicated for $3 \mathrm{~min}$ (Ultrasonic Processor XL, Misonix) and divided into six parts. Next, the appropriate $\mathrm{pH}$ value $(3 ; 4.5 ; 5.5 ; 6.5 ; 8$ and 10$)$ was adjusted in each sample and its potential zeta was measured. The value of the zeta potential was calculated with a suitable computer program using the Smoluchowski equation.

\section{Results and discussion}

Figures 2 and 3 show the adsorption isotherms of polyacrylic acid with molecular weight 240,000 on the surfaces of SA-3 and SA-96 determined at different $\mathrm{pH}$ values (i.e., 3, 6, and 9). For the two other molecular weights of PAA $(2,000$ and 100 , 000), similar dependencies were obtained. As can be seen in 


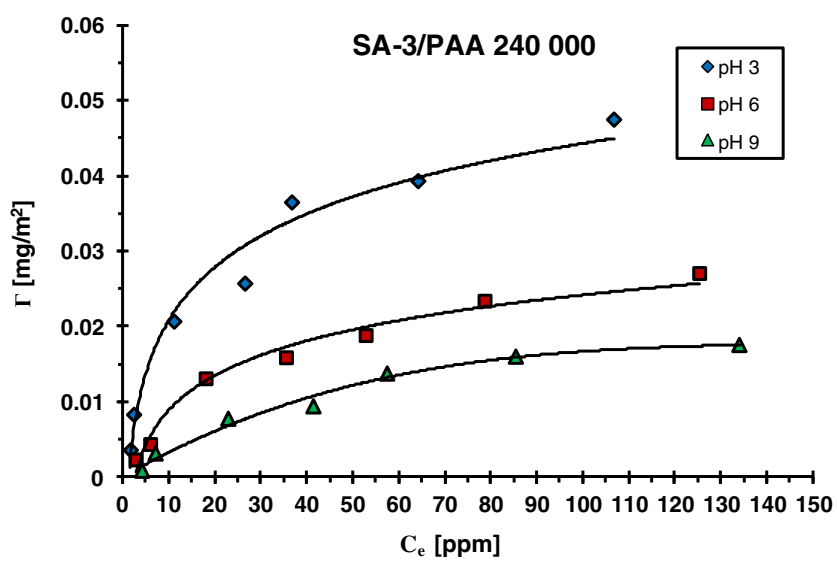

Fig. 2 Adsorption isotherms of PAA 240,000 on the SA-3 surface at different solution $\mathrm{pH}$ values

these figures, the solution $\mathrm{pH}$ at which the polymer adsorption takes place has a significant influence on its amount. Analysis of presented isotherms leads to the conclusion that PAA adsorption on the mixed oxide surface decreases with the increasing $\mathrm{pH}$ of the solution. The $\mathrm{pH}$ changes affect the process of carboxyl groups' dissociation in the polymer chains which result in the changes of ionization of polyacrylic acid macromolecules. The pK of PAA is equal to 4.5; thus, before reaching this $\mathrm{pH}$ value, the undissociated carboxyl groups $\mathrm{COOH}$ predominate in the polymer chain over the dissociated ones $-\mathrm{COO}^{-}$. At $\mathrm{pH} 4.5$, the number of undissociated carbox$\mathrm{yl}$ groups is the same as that of dissociated ones. Further, $\mathrm{pH}$ increase above the value 4.5 results in dissociation of the remaining carboxyl groups. At $\mathrm{pH}$ 6, PAA macromolecules are already almost completely ionized [degree of dissociation $(\alpha)$ is equal to 0.97 ] [25].

On the other hand, the surface charge density of the adsorbents has the crucial effect on the interactions between the adsorbent and the adsorbate. Figures 4 and 5 present, among others, the surface charges of examined oxides as a function of $\mathrm{pH}$. The points of zero charges are at the $\mathrm{pH}$ values: 3.4 for

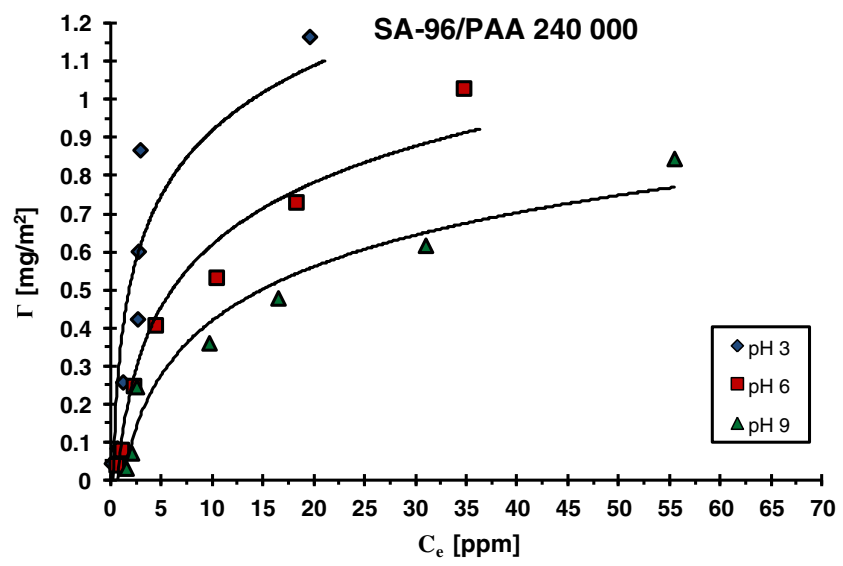

Fig. 3 Adsorption isotherms of PAA 240,000 on the SA-96 surface at different solution $\mathrm{pH}$ values

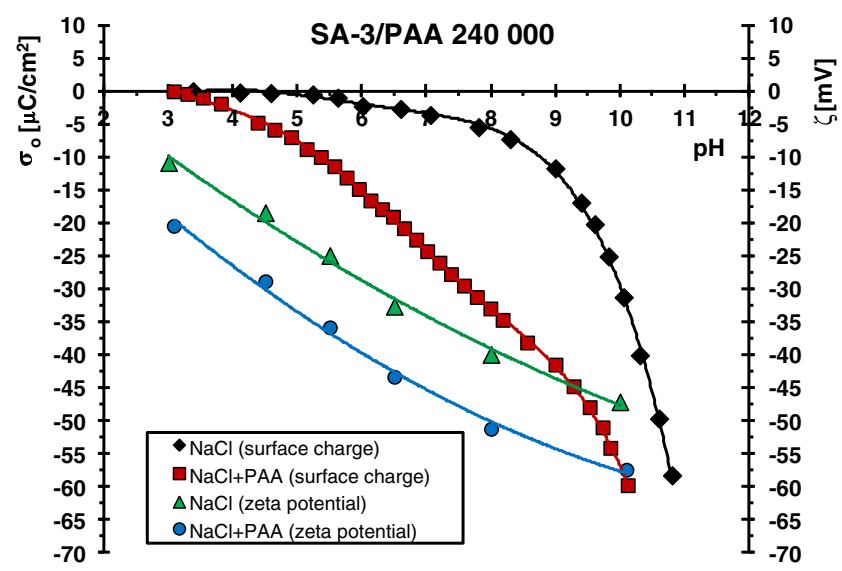

Fig. 4 Surface charge density $\left(\sigma_{\mathrm{o}}\right)$ and zeta potential $(\zeta)$ of SA-3 particles in the absence and presence of PAA 240,000

SA-3 and 7.6 for SA-96. At these $\mathrm{pH}$ values, the total surface charge is equal to zero, which means that the numbers of positively and negatively charged surface groups are the same.

Taking above into consideration, it can be stated that in the case of the SA-3/PAA systems (Figs. 2 and 4), the electrostatic repulsion between the solid surface and the polymer chains occurs almost in the whole examined $\mathrm{pH}$ range. For this reason, the polymer adsorption decrease with the $\mathrm{pH}$ rise is a result of the increasing repulsion between the dissociating PAA macromolecules and more negative solid surface. Under such conditions, the polymer adsorption on the SA-3 surface undergoes through hydrogen bridges and chemical bonds [28, 29]. It results from the fact that carboxyl groups of the polymer can act both as a donor and an acceptor of protons. Thus, adsorbate-adsorbent bonding can proceed between all types of solid surface groups (negative, positive, and neutral) and undissociated and dissociated PAA functional groups.

A little different situation takes place in the case of the SA96/PAA systems (Figs. 3 and 5). $\mathrm{pH}_{\mathrm{pzc}}$ of this oxide is 7.6 and in the $\mathrm{pH}$ values below 7.6 attractive interactions between the dissociated carboxyl groups of PAA and the positively

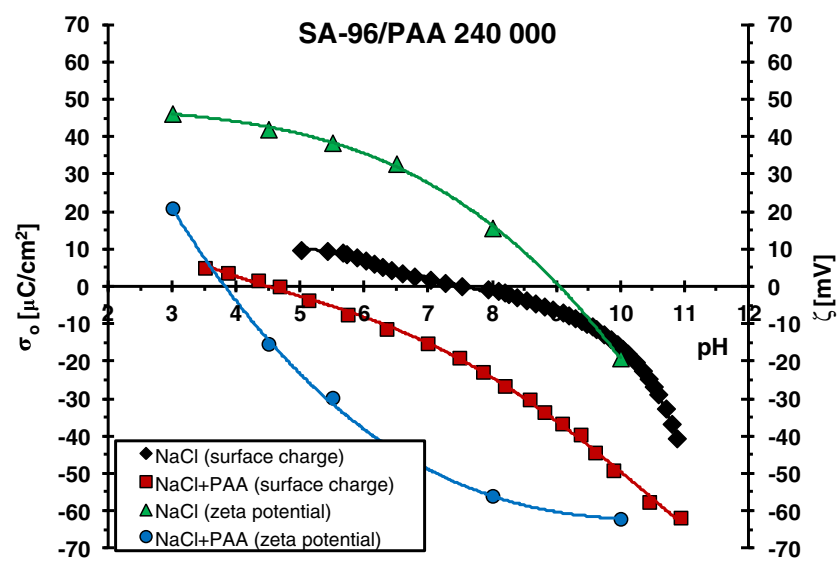

Fig. 5 Surface charge density $\left(\sigma_{\mathrm{o}}\right)$ and zeta potential $(\zeta)$ of SA-96 particles in the absence and presence of PAA 240,000 
charged surface take place. Such adsorbent-adsorbate attractions cause a significant increase of the polymer adsorption at $\mathrm{pH} 3$. Another factor which promotes the adsorption of PAA is its specific conformation. At $\mathrm{pH} 3$, PAA macromolecules contain a small number of $-\mathrm{COO}^{-}$groups (dissociation degree 0.03 ), and they adsorb on the SA-96 surface in the form of polymeric coils. Such a structure of the adsorbed chains leads to the formation of densely packed polymer films. As a result, the highest adsorption of polyacrylic acid at $\mathrm{pH} 3$ is observed. More and more extended conformation of adsorbing polymer chains with the increasing $\mathrm{pH}$ and the weakening attraction gradually passing into repulsion leads to pronounced reduction in polymer adsorption. However, despite unfavorable electrostatic repulsion at $\mathrm{pH}>7.6$, PAA adsorption takes place. This fact proves that specific interactions, which include hydrogen and chemical bonds, are responsible for the binding of polymer macromolecules with the solid surface.

Electrostatic repulsion polymer surface occurring practically in the whole range of studied $\mathrm{pH}$ in the case of SA-3 causes minimal adsorption of PAA on its surface. Table 2 presents the comparison of adsorbed amounts $(\Gamma)$ of PAA (with various molecular weights) on the SA-3 and SA-96 surfaces at different solution $\mathrm{pH}$ values (obtained for the initial PAA concentration $100 \mathrm{ppm}$ ). The adsorbed amounts of polyacrylic acid are several (2 or 3) dozen times higher on the SA-96 surface than those observed on the SA-3 surface. A much greater adsorption affinity of PAA chains to the SA-96 surface is mainly due to the favorable attractive interactions which are present in the system at the $\mathrm{pH}$ range below $\mathrm{pH}_{\mathrm{pzc}}$ (namely at $\mathrm{pH}<7.6$ ). The electrostatic repulsion between the PAA and SA-96 surface appearing at $\mathrm{pH}>7.6$ is similar to that obtained in the case of the adsorbent SA-3. For both applied mixed oxides, the surface charge density changes in the $\mathrm{pH}$ range 7.6 to 9 from -4.5 to $-11.9 \mu \mathrm{C} / \mathrm{cm}^{2}$ for SA-3 (Fig. 4) and from 0.12 to $-7.1 \mu \mathrm{C} / \mathrm{cm}^{2}$ for SA-96 (Fig. 5). It means that electrostatic repulsion in this $\mathrm{pH}$ range has similar strength for both adsorbents. Thus, the adsorption of polymer in this $\mathrm{pH}$ range must be determined by the concentration of neutral $\mathrm{MeOH}$ ( $\mathrm{Me}$ - metal atom: $\mathrm{Si}$ or $\mathrm{Al}$ ) surface groups. The previous study [30] showed that the concentration of these surface groups is several dozen times larger than that of charged ones (positive $-\mathrm{MeOH}_{2}^{+}$and negative $-\mathrm{MeO}^{-}$). In

Table 2 Comparison of adsorbed amounts $(\Gamma)$ of PAA on the SA-3 and SA-96 surfaces at different solution $\mathrm{pH}$ values for $\mathrm{C}_{\mathrm{PAA}}=100 \mathrm{ppm}$

\begin{tabular}{|c|c|c|c|c|c|c|}
\hline \multirow[t]{2}{*}{ Polymer } & \multicolumn{3}{|l|}{ SA 3} & \multicolumn{3}{|l|}{ SA 96} \\
\hline & $\mathrm{pH}=3$ & $\mathrm{pH}=6$ & $\mathrm{pH}=9$ & $\mathrm{pH}=3$ & $\mathrm{pH}=6$ & $\mathrm{pH}=9$ \\
\hline PAA 2,000 & 0.02 & 0.015 & 0.013 & 0.64 & 0.59 & 0.51 \\
\hline PAA 100,000 & 0.03 & 0.02 & 0.015 & 0.78 & 0.63 & 0.58 \\
\hline PAA 240,000 & 0.04 & 0.03 & 0.016 & 0.86 & 0.73 & 0.62 \\
\hline
\end{tabular}

the case of alumina, the concentration of neutral groups on its surface in the $\mathrm{pH}$ range $7-9$ is about $120 \mu \mathrm{C} / \mathrm{cm}^{2}$ [31], whereas for silica, it is about a few microcoulombs per cubic centimeter (on average $7 \mu \mathrm{C} / \mathrm{cm}^{2}$ ) [32].

Taking this fact into consideration, one can assume that in the case of SA-96 surface, the number of neutral surface groups must be significantly greater in comparison to SA-3. For this reason, despite comparable repulsion between the polymer and the adsorbent in the case of both examined oxides, the adsorbed amount of PAA is considerably greater on the SA-96 surface. This great affinity of PAA chains for the SA-96 surface under such $\mathrm{pH}$ conditions probably results from the possibility of formation of a greater number of connections between the polymer segments and $-\mathrm{MeOH}$ surface groups (whose concentration must much greater in the case of SA-96).

The confirmation of the PAA adsorption mechanism proposed above is thicknesses of its adsorption layers on the surfaces of studied oxides. The comparison of adsorption layer thicknesses $(\delta)$ of PAA (with various molecular weights) on the SA-3 and SA-96 surfaces at different solution $\mathrm{pH}$ values is presented in Table 3. The analysis of these data indicates that $\delta$ increases with the $\mathrm{pH}$ rise. Moreover, for all examined molecular weights of polyacrylic acid, thicker adsorption layers of PAA are formed on the SA-3 surface.

The increase of thickness of PAA adsorption layers with the increasing $\mathrm{pH}$ results from rising dissociation of carboxyl groups in the polymer chains and changes in the sign of surface charge from positive to negative (at $\mathrm{pH} 3.4$ for SA-3 and at $\mathrm{pH} 7.6$ for SA-96). Mutual repulsion between the growing number of dissociated- $\mathrm{COO}^{-}$groups in the PAA macromolecules leads to their straightening as $\mathrm{pH}$ rises. On the other hand, the process of developing of the polymer chains is amplified by the weakening attraction of them to the surface and after exceeding the $\mathrm{pH}_{\mathrm{pzc}}$ by electrostatic repulsion. As a result, the higher the solution $\mathrm{pH}$ is, the thicker the polymer adsorption layer is.

Additionally, in the case of SA-3, the thicker PAA adsorption layers are formed in comparison to those obtained for SA96. The main reason for such behavior is small affinity of polyacrylic acid macromolecules for the SA-3 surface. As a result, a few polymer segments are binding to the active sites

Table 3 Comparison of adsorption layer thicknesses $(\delta)$ of PAA on the SA-3 and SA-96 surfaces at different solution $\mathrm{pH}$ values for $\mathrm{C}_{\mathrm{PAA}}=$ $100 \mathrm{ppm}$

\begin{tabular}{llllllll}
\hline Polymer & \multicolumn{1}{l}{$\mathrm{SA} 3$} & \multicolumn{5}{c}{$\mathrm{SA} 96$} \\
\cline { 2 - 4 } \cline { 7 - 8 } & $\mathrm{pH}=3$ & $\mathrm{pH}=6$ & $\mathrm{pH}=9$ & & $\mathrm{pH}=3$ & $\mathrm{pH}=6$ & $\mathrm{pH}=9$ \\
\hline PAA 2,000 & 2.8 & 5.3 & 9.6 & 2.0 & 4.8 & 7.4 \\
PAA 100,000 & 3.6 & 7.4 & 10.1 & 3.5 & 5.1 & 8.3 \\
PAA 240,000 & 4.9 & 9.0 & 11.7 & 4.3 & 7.9 & 10.0 \\
\hline
\end{tabular}


on the surface of the adsorbent, so that the conformation of the adsorbed macromolecule is rich in long loop and tail structures. In the case of SA-96, the adsorbed polymer chains have flatter conformation due to the larger number of direct connections of PAA segments with the surface $-\mathrm{MeOH}$ groups, which in the case of this solid must be much more. Also of importance is the fact of the presence of electrostatic repulsion between the PAA chains and the SA-3 surface practically in the whole range of studied $\mathrm{pH}$. It affects a significant expansion of adsorbed macromolecules in perpendicular direction to the solid surface, which is reflected in the increase of the thickness of the polymer adsorption layer formed in the SA3/PAA systems.

As can be seen in Figs. 4 and 5, polyacrylic acid adsorption causes lowering of both oxide surface charge density $\left(\sigma_{\mathrm{o}}\right)$ and zeta potential $(\zeta)$ of solid particles. Such tendency was observed for both examined mixed oxides and for all used molecular weights of PAA. Considering the fact that the presence of PAA with the highest molecular weight causes the greatest reduction in these two parameters, in this paper, respective results for the mixed oxide/PAA 240,000 systems are presented.

Lowering of the surface charge of both adsorbents in the presence of polyacrylic acid is a result of the two effects. On one hand, the dissociated carboxyl groups of the polymer, which undergo the direct binding to the solid surface cause increase of the solid surface charge (usually anionic compounds adsorption forces the formation of positively charged groups on the surface). On the other hand, only a few polymer segments are binding to the adsorbent surface; the overwhelming majority of them are in the solution building loop and tail structures of adsorbed macromolecules. The presence of ionized carboxyl groups belonging to these segments, located in the Stern layer, leads to decrease of the solid surface charge. This latter effect is predominant over the first one because of a much larger number of segments located in the loops and tails compared to the train structures (formed by the polymer segments which are directly connected with the solid surface). As a consequence, the final result of the polyacid adsorption is reduction of the surface charge of mixed oxide.

Three main reasons are responsible for the changes of zeta potential of solid particles in the presence of polymeric substances. These are (a) the presence of functional groups in polymer chains which are capable of dissociation, (b) the shift of slipping plane from the solid surface due to the formation of the polymer adsorption layer [26], and (c) the blockade of solid active sites by the previously adsorbed polymer chains, as a result, they become unavailable for supporting electrolyte ions. The contributions of these effects influence the final value of zeta potential.

As can be seen in Figs. 4 and 5, the changes of zeta potential of oxide particles in the PAA presence in comparison to that in the polymer absence is considerably greater in the case of the system containing SA-96. The difference of $\zeta$ value (between that for the system without and with PAA) at a given $\mathrm{pH}$ value is even $70 \mathrm{mV}$ for SA-96 (at $\mathrm{pH}$ 8), whereas for SA-3, this difference is at the level of 10 or $15 \mathrm{mV}$. The effect of slipping plane shift is undoubtedly responsible for reduction of zeta potential of solid particles covered with polyacrylic acid for all examined adsorbents. Nevertheless, the significantly greater reduction of zeta potential in the system SA 96/PAA in comparison to SA-3/PAA results from the presence of a much larger number of $-\mathrm{COO}^{-}$ groups of polymer chains in the diffusion part of the electrical double layer around the solid particle. Such a high concentration of dissociated carboxyl groups in the slipping plane is a result of large adsorption of PAA on the SA-96 surface and less stretched conformation of the adsorbed macromolecules (in perpendicular direction to the solid surface). In the case of the SA-3/PAA system, the polymer adsorption is small and adsorbed chains conformation is more extended, which makes that the packing of the adsorption layer is low and the content of the $-\mathrm{COO}^{-}$groups in the diffusion layer is also small. It leads to far lower reduction of zeta potential of SA-3 particles in the polyacrylic acid presence in comparison to that obtained for the SA-96/PAA system.

The blockade of solid active sites by the previously adsorbed polymer chains may have an effect on the zeta potential changes. It occurs especially in the situation in which the adsorbed macromolecules form flatter conformation and densely packed adsorption layer, i.e., for the system containing SA-96. In such a case, the supporting electrolyte ions are desorbed from the solid surface by the adsorbing polymer chains and they are removed to the diffusion area, influencing the zeta potential of solid particles.

\section{Conclusions}

Of the two examined mixed oxides (SA-3 and SA-96), significantly greater affinity for the adsorption of anionic polyacrylic acid is exhibited by SA-96. It results from much more favorable electrostatic interactions occurring between the polymer chains and the SA-96 surface (attractive forces in the $\mathrm{pH}$ range 3-7.6). As a consequence, the PAA adsorption layer formed on the SA-96 surface is characterized by high packing and the adsorbed macromolecules are flatter conformation (thinner adsorption layer). In the case of the SA-3/PAA system, polymer adsorption is small due to the electrostatic repulsion between the PAA chains and the solid surface occurring practically in the whole range of studied $\mathrm{pH}$ (3.4-9). As a result, the polymeric adsorption layer on the SA-3 surface is thicker. The hydrogen bridges are responsible for PAA adsorption on the mixed oxide surface, especially under the conditions of electrostatic adsorbate-adsorbent repulsion. Moreover, the presence of PAA causes lowering of surface 
charge and zeta potential of solid particles in comparison to the system without polymer. The effect of zeta potential reduction is considerably greater in the case of the SA-96 / PAA suspension, mainly due to high concentration of dissociated carboxyl groups of polymer chains in the slipping plane area around the solid particle.

Open Access This article is distributed under the terms of the Creative Commons Attribution License which permits any use, distribution, and reproduction in any medium, provided the original author(s) and the source are credited.

\section{References}

1. Nosal-Wiercińska A (2012) Adsorption of cystine at mercury/ aqueous solution of chlorate (VII) interface in solutions of different water activity. Cent Eur J Chem 10:1290-1300

2. Nosal-Wiercińska A, Grochowski M (2011) Adsorption of thiourea and its methyl derivatives from chlorate(VII) with varied water activity. Coll Czech Chem Comm 76:265-275

3. Grządka E, Chibowski S (2012) Adsorption and electrokinetic properties of the system: carboxymethylcellulose/manganese oxide/ surfactant. Cellulose 19:23-36

4. Grzadka E (2011) Competitive adsorption in the system: carboxymethylcellulose/ surfactant/ electrolyte/ $\mathrm{Al}_{2} \mathrm{O}_{3}$. Cellulose 18:291-308

5. Napper DH (1983) Polymeric stabilization of colloidal dispersions. Academic, London

6. Chaiwong N, Nuntiya A (2008) Influence of $\mathrm{pH}$, electrolytes and polymers on flocculation of kaolin particle. Chiang Mai J Sci 35:11-16

7. Somasundaran P, Runkana V (2005) Investigation of the flocculation of colloidal suspension by controlling adsorbed layer microstructure and population balance modeling. Chem Eng Res Des 83:905-914

8. Ueno K, Inaba A, Kondoh M, Watanabe M (2008) Colloidal stability of bare and polymer-grafted silica nanoparticles in ionic liquids. Langmuir 24:5253-5259

9. Tripathy T, De BR (2006) Flocculation: a new way to treat the waste water. J Phys Sci 19:93-127

10. Gurumoorthy AVP, Kha KH (2011) Polymers at interfaces: biological and non-biological applications. Rec Res Sci Tech 3:80-86

11. Roberts JC (1996) Paper chemistry. Chapman \& Hall, London

12. Sojka RE, Bjorneberg DL, Entry JA, Lentz RD, Orts WJ (2007) Polyacrylamide in agriculture and environmental land management. Adv Agron 92:75-162

13. Tadros TF (2008) Colloids aspects of cosmetic formulations with particular reference to polymeric surfactants. Colloids Interf Sci Ser 4:1-34

14. Shahidi F, Arachchi JKV, Yeon YJ (1999) Food application of chitin and chitosans. Trends Food Sci Tech 10:37-51
15. Jin YZ, Zhang YF, Chen XP, Gao HS (2003) Application of organic polymeric flocculants in centrifugal dewatering of oil refinery sludge. J Environ Sci (China) 15:510-513

16. Moody G (1992) The use of polyacrylamides in mineral processing. Min Eng 5:479-492

17. Gawande MB, Pandey RK, Jayaram RV (2012) Role of mixed metal oxides in catalysis science - versatile applications in organic synthesis. Catal Sci Technol 2:1113-1125

18. Guidelli EJ, Guerra EM, Mulato M (2012) Vanadium and titanium mixed oxide films: synthesis, characterization and application as ion sensor. J Electrochem Soc 159:J217-J222

19. Kaciulis S, Pandolfi L, Viticoli S, Sberveglieri G, Zampiceni E, Wlodarski W, Galatsis K, Li YX (2002) Investigation of thin films of mixed oxides for gas-sensing applications. Surf Interf Anal 34: $672-676$

20. Weilong W, Xiaobo F (2013) Efficient removal of Cr(VI) with Fe/Mn mixed metal oxide nanocomposites synthesized by a grinding method. J Nanomater ID 514917:1-8

21. Wiśniewska M, Terpiłowski K, Chibowski S, Urban T, Zarko VI, Gun'ko VM (2013) Effect of polyacrylic acid (PAA) adsorption on stability of mixed alumina - silica oxide suspension. Powder Tech 233:190-200

22. Wiśniewska M, Terpiłowski K, Chibowski S, Urban T, Zarko VI, Gun'ko VM (2013) Effect of solution pH on the stability of mixed silica-alumina suspension in the presence of polyacrylic acid (PAA) with different molecular weights. Cent Eur J Chem 11:101-110

23. Gun'ko VM, Zarko VI, Turov VV, Leboda R, Chibowski E, Holysz L, Pakhlov EM, Voronin EF, Dudnik VV, Gornikov YI (1998) CVDtitania on fumed silica substrate. J Colloid Interf Sci 198:141-156

24. Michaels AS, Morelos O (1955) Polyelectrolyte adsorption by kaolinite. Ind Eng Chem 47:1801-1809

25. Wiśniewska M, Chibowski S (2005) Influences of temperature and purity of polyacrylic acid on its adsorption and surface structures at $\mathrm{ZrO}_{2}$-polymer solution interface. Adsorpt Sci Technol 23:655-667

26. Crummett WB, Hummel RA (1963) The determination of traces of polyacrylamides in water. J Am Water Works Assoc 1:209-219

27. M'Pandou A, Siffert B (1987) Polyethylene glycol adsorption at the $\mathrm{TiO}_{2}-\mathrm{H}_{2} \mathrm{O}$ interface: distortion of ionic structure and shear plane position. Colloids Surf 24:159-172

28. Kasprzyk-Hordern B (2004) Chemistry of alumina, reactions in aqueous solution and its application in water treatment. Adv $\mathrm{J}$ Colloid Interf Sci 110:19-48

29. Wiśniewska M (2008) Temperature dependence of polyacrylic acid adsorption on the alumina surface; free energy of polymer adsorption. Pol J Chem 82:159-169

30. Chibowski S, Wiśniewska M (2001) Study of the adsorption mechanism and the structure of adsorbed layers of polyelectrolyte at metal oxide-solution interface. Adsorpt Sci Technol 19:409-421

31. Chibowski S, Paszkiewicz M (2007) Competitive adsorption of polyacrylic acid (PAA) and polyvinyl alcohol (PVA) at $\mathrm{Al}_{2} \mathrm{O}_{3} /$ solution interface. Surfactant Dispers Syst Theory Pract 283-286

32. Janusz W (1999) Electrical double layer at the metal oxide-electrolyte interface in "interfacial forces and fields: theory and applications", vol 85. M. Dekker, New York, Chapter 4 